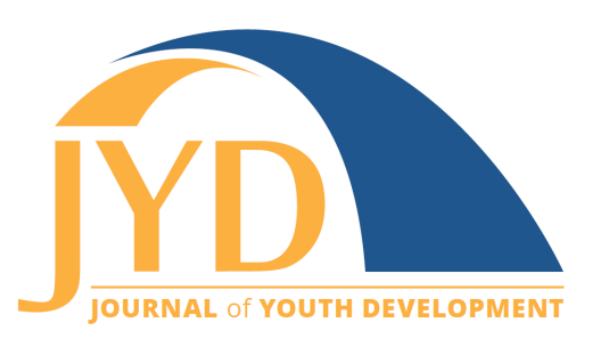

http://jyd.pitt.edu/ | Vol. 16 Issue 2-3 DOI 10.5195/jyd.2021.1071 | ISSN 2325-4017 (online)

\title{
Agency and Empowerment for Adolescent Girls: An Intentional Approach to Policy and Programming
}

\author{
Prerna Banati \\ UNICEF \\ pbanati@unicef.org \\ Lauren Rumble \\ UNICEF \\ Irumble@unicef.org \\ Nicola Jones \\ Overseas Development Institute \\ n.jones@odi.org.uk

\section{Sarah Hendriks} \\ UN Women \\ sarah.hendriks@unwomen.org
}

\begin{abstract}
As national governments roll out COVID response plans, an opportunity arises to re-cast adolescent girls' programs to centrally anchor them on girls' voices, leadership, ambitions, and assets in development policies and programs. Drawing together the evidence on what we know works for adolescent girls, as well as the growing literature on positive strengths-based programming which are gradually and increasingly being applied, this commentary calls for a girl-intentional approach to policy and programming. A girl-intentional approach is described through 3 case studies, which illustrate the additionality of new or improved adolescent knowledge, skills, and competencies; improved opportunities for adolescent engagement, voice, and agency; improved community safety and support; stronger, healthier relationships; and stronger and healthier norms, attitudes, values, and goals. The case studies describe program hooks that facilitate operationalization, point to measurable outcomes, and identify opportunities for scale, including the re-opening of schools. Overall, inter-sectoral solutions that address the myriad of issues affecting an adolescent girl's life and tackle pervasive gender inequities require greater emphasis by development actors and national governments.
\end{abstract}

Key words: adolescent girls, gender equality, empowerment, participation

(cc) EY New articles in this journal are licensed under a Creative Commons Attribution 4.0 License. This journal is published by the University Library System, University of Pittsburgh and is cosponsored by the University of Pittsburgh Press. The Journal of Youth Development is the official peer-reviewed publication of the National Association of Extension 4-H Youth Development Professionals and the National AfterSchool Association. 


\section{Agency and Empowerment for Adolescent Girls}

Adolescence, regardless of where you live, can be a turbulent period of life, but also a period of immense opportunity. For girls, transitions through adolescence can be hazardous and pose particular challenges, especially under conditions where social and economic constraints place additional burdens, in part due to the deeply embedded gender norms which determine her actions, her opportunities, and how she interacts with society (Harper et al., 2018). Where there are no barriers to accessing health services and education, and where opportunities for voice exist, girls are able to live empowered and fulfilling lives (Banati \& Lansford, 2018; Jones et al., 2018), with positive gains for herself, her community and society as a whole. Evidence shows high rates of return in investments in girls' education (UNESCO, 2014) and preventing child marriage (Wodon et al., 2017), for society and centrally for the girl herself.

Entering adulthood is increasingly complex today. New and emerging threats have been identified, including the climate crisis, increasingly vulnerable ${ }^{1}$ and under-employment, health epidemics, and rising forced displacement, as well as insecurity, protracted conflicts, and growing violence (Gharabaghi \& Anderson-Nathe, 2018; Jones et al., 2019; Majeed and Lee, 2017). Many of these disproportionality impact girls. Climate shocks and humanitarian crises, including global pandemics such as HIV and COVID-19, amplify pre-existing inequalities and present real risks of increasing child marriage, violence, school drop-out, and restricted access to social services (Banati et al., 2020; Jones et al., 2020; UNICEF, 2020; UN Women, 2020b). For example, adolescent girls are vulnerable to the impact of climate change and research finds that early marriage is used as a strategy to cope with climate shocks (Carrico et al., 2020; UN Women, 2017.) As national governments roll out COVID response plans, an opportunity arises to recast adolescent girls' programs to centrally anchor them on girls' voices, leadership, ambitions, and assets in development policies and programs.

Historically, public sector strategies for adolescents and youth have tended to focus on protection from or prevention of problems and responding to them when they occurred (Banati \& Camilletti, 2018), with limited participation and feedback from adolescents. The need for a delicate balance is particularly evident in setting minimum ages where the science of young people's evolving capacities makes clear that inappropriate application can compromise protection and jeopardize adolescents' agency and choice. In a recent analysis in South Asia, legal and policy indicators in many countries have set minimum ages, for example for criminal

\footnotetext{
${ }^{1}$ Workers in vulnerable employment "are less likely to have formal work arrangements, and are therefore more likely to lack decent working conditions, adequate social security and 'voice' through effective representation by trade unions and similar organizations. Vulnerable employment is often characterized by inadequate earnings, low productivity and difficult conditions of work that undermine workers' fundamental rights" (ILO, 2010).
} 


\section{Agency and Empowerment for Adolescent Girls}

responsibility, at a lower level compared to those prescribed by international standards, or by applying legal conditions of marriage as exceptions to age of consent to sexual activity (Camilletti, 2018). And similarly, some researchers have argued that laws that promote a high age of sexual consent are frequently used to curb adolescents' and women's agency, resulting in stigmatization and criminalization (Petroni et al., 2019).

In recent years, several UN agencies and development partners have advocated for approaches that redress this imbalance by placing emphasis on the competencies, assets and agency of adolescents, with dedicated strategies to reach and support adolescent girls. These have focused on advancing the capabilities of adolescent girls while recognizing that complex challenges faced by this group may have multiple root causes and dependencies across outcomes. Available research, whilst still limited, reveals a growing body of evidence-based effective interventions for girls' health and well-being, including to achieve positive sexual and reproductive health (Chandra-Mouli et al., 2015.), eliminate child marriage (Malhotra et al., 2011), prevent violence (Kerr-Wilson et al., 2020), improve girls' nutrition (Lassi et al. 2017) or good mental health (Das et al., 2016). Through these rich systematic reviews, we have a good idea of the determinants to and pathways towards outcomes, as well as necessary components of specific interventions that can guide us towards effective programming and policy responses.

However, there is an acknowledgement that these have had significant implementation challenges. The lack of available quality services, especially in low- and middle-income settings remain a challenge. Weak systems are coupled with limited integration. There remain many one-off interventions without enduring impacts. There is a lack of national capacity to implement gender-transformative programs even in high income countries, and these rarely operate at scale. Economic barriers including transport costs hamper access to services, including education. Girls remain underprioritized in national frameworks and budgets, particularly with respect to issues like gender-based violence and mental health (Woldeyesus et al., 2018).

Furthermore, at the community level there is a need to address the gender-related barriers that prevent women and girls from demanding the realization of their rights, including to information and health services. These barriers include unequal gender norms, household responsibilities such as care work and farming, which may prevent adolescent girls access to sexual and reproductive health services (Shrestha et al., 2020). Additionally, girls may not have autonomous decision-making power over their own health and need to seek permission from their parents to visit the clinic (World Health Organization [WHO], 2018). 


\section{Agency and Empowerment for Adolescent Girls}

There is less information available about how to support girls' own activism and agency in policy and programs. Policymakers and community leadership structures tend to be resistant to meaningful participation and skeptical of adolescent girls' engagement; all the while harmful social norms continue to be perpetuated in many parts of the world. Across the globe, we have seen a growth of regressive national politics in recent years which has had significant impacts on policy options with direct influence on girls' lives and investments in solutions led by girls for girls are not consistently funded or supported. Young feminists are increasingly calling for a rethinking of development; emphasizing the centrality of girls' own voices and leadership in humanitarian response and development efforts (Bashi et al., 2018). Finally, there remains insufficient alignment between program interventions and robust evidence collection for learning and adaptive management.

At the same time, positive adolescent development approaches-which converge around a strengths-based conception of adolescence and recognize capabilities, assets, and agency as important contributors to problem-solving (Lerner, 2005)_are gradually and increasingly being applied, including to address persistent gender inequities. Serving as a framework for adolescent and youth programs in high-income countries since the early 1990s and more recently in low- and middle-income settings, these intentional, prosocial approaches engage adolescent girls and boys within their communities, schools, organizations, peer groups, and families in a manner that is productive and constructive, recognizing, utilizing, and enhancing their strengths (Catalano et al., 2019). These programs, (which are characterized by the Five Cs: competence, confidence, connection, character, and caring) have demonstrated a wide range of benefits for young people through building skills, assets, and competencies; fostering youth agency; building healthy relationships; increasing youth contributions; strengthening the enabling environment; and transforming systems to prepare young people for successful adulthood (Catalano et al., 2019). However, because these programs are often delinked from well-accepted PYD and well-being outcomes and poorly measured, donors remain skeptical of investing in these approaches (Simac et al., 2019).

There are a few notable examples that have-to varying degrees, and in varying ways-brought together these approaches. We share three here with different aims: one to tackle child marriage, a second responding to skills and safety gaps, and a third addressing HIV. We seek to share examples from both humanitarian and development settings. These programs have, with intentionality, introduced adolescent agency and pro-social methods with the goal of amplifying the development impact of existing interventions. In each example, we seek to identify program 


\section{Agency and Empowerment for Adolescent Girls}

opportunities or hooks, facilitate operationalization, and point to measurable outcomes for adolescent girls and beyond. In particular, the examples illustrate the additionality of (a) new or improved adolescent knowledge, skills, and competencies; (b) improved opportunities for adolescent engagement; (c) improved community safety and support; (d) stronger, healthier relationships; or (e) stronger and healthier norms, attitudes, values, and goals.

\section{Balika Project, Bangladesh}

The BALIKA (Bangladeshi Association for Life Skills, Income, and Knowledge for Adolescents) program was designed to tackle the high rates of child marriage in Bangladesh - where two out of three girls are married before age 18 (Population Council 2020). The program works with 12 to 18 year-old girls in their communities to implement holistic programs to build skills. Over 9,000 girls in 72 communities took part. Three different interventions were implemented over 18 months in 2014 and 2015: (a) education support, where girls in school received tutoring in mathematics and English, while girls out of school received computing or financial skill training; (b) life-skills training which included training on gender rights and negotiation, critical thinking, and decision making; or (c) livelihoods training where girls received training in entrepreneurship, mobile phone servicing, photography, and basic first aid.

On a weekly basis, all participating girls met with mentors and peers in safe, girl-only locations. Basic life skills training was provided to all participating girls. In the safe spaces they were able to make friends, receive training on new technologies, or borrow books. The safe spaces were managed by locally recruited young women mentors (only slightly older than participants) with the assistance of a teacher affiliated with the school that housed the center and worked parttime with the project after school hours. The teachers and mentors recruited girls to the program, liaised with families and communities, and engaged with the community support groups. The teachers and mentors were the primary link between the program and the community and were important role models and mentors for adolescent girls. Project supervisors observed sessions in each girls' group and interacted with mentors to provide regular feedback to improve the facilitation sessions using a rating system that fed into the project's monitoring system.

The Balika program deliberately set out to achieve positive outcomes for and with adolescent girls. The goal of program was to encourage girls (aged 12 to 18) to build their social assets, increase their confidence and articulate their successes and achievements. In doing so, girls could demonstrate their value and amplify their status in the communities in which they lived. 


\section{Agency and Empowerment for Adolescent Girls}

Results found girls who were single at the beginning of the study were $25 \%$ less likely to be married by the end of the study. Analysis shows that with each intervention it was possible to significantly delay child marriage in comparison to control communities. Girls who received educational support were $31 \%$ less likely to be married as children. Girls who received life skills training on gender rights and negotiation, critical thinking, and decision making were $31 \%$ less likely to be married as children. Girls who received livelihoods training in entrepreneurship, mobile phone servicing, photography, and basic first aid were $23 \%$ less likely to be married before age 18. Participating girls were more likely than their non-participating counterparts to be attending school, have improved mathematical skills, and be earning an income. Whether the results of the program can be sustained will be an important area of inquiry going forward.

In 2017, recognizing the positive contribution of mentoring, girl-only safe spaces, and life skills training, which together were central to building agency among girls in the program, the Population Council, UNFPA, UNICEF, and the Bangladesh Ministry of Women and Children Affairs scaled up the BALIKA program into new districts in Bangladesh as part of a broader program to delay early marriage.

\section{Makani Program, Jordan}

The Makani (My space) program for vulnerable children and adolescents in Jordan was designed initially to provide support to Syrian refugees when they had limited access to formal education in the early years of the Syrian crisis. It is managed by UNICEF Jordan and implemented by a network of international and local NGO partners and government agencies in host communities, and by Syrian volunteers in Azraq and Zatari refugee camps. Over time as investments by the Government of Jordan and development partners have expanded formal education places through a double shift school system, the program has evolved to focus on a package of support to vulnerable young people in both refugee and host communities. This includes learning support services in core education subjects (including math, Arabic, English and science), science and technology innovation labs for older adolescents, life skills training, child protection, psychosocial support, sports, and more recently linkages with a labelled cash transfer for education program, Hajati (My needs). The program's multi-dimensional objectives are encapsulated in the motto "I am safe, I learn, I connect" and focus on supporting refugee children to connect with peers and trusted adults in a safe space and to develop their voice and confidence as they learn new skills. The program also aims to provide services for parents, to strengthen community social cohesion between refugees and host communities, and to ensure that children in need of specialist services (e.g., mental health or child protection) are identified 


\section{Agency and Empowerment for Adolescent Girls}

and referred. In 2018 the program reached approximately 102,719 adolescents (54\% of whom were girls) and 40,000 adults in 150 centers across the country.

In terms of program outcomes, a mixed methods evaluation involving approximately 4000 adolescents undertaken by the Gender and Adolescence: Global Evidence (GAGE) program involving both Makani and non-Makani participants with similar background characteristics ${ }^{2}$ found evidence of a range of positive outcomes for adolescent girls and other program participants. In terms of new knowledge and skills, GAGE survey findings revealed that Makani attendees, in addition to having significantly improved math scores than non-participants, were much more likely to play a sport than non-participants (adolescent girl program participants were twice as likely to be involved in sport-25\% for participants vs $12 \%$ for non-participantsand for boys the differential was $51 \%$ vs. $38 \%$ ); and that girls enjoyed improved digital connectivity and knowledge (participants were $17 \%$ more likely to be allowed to use the Internet). Adolescents attending Makani also scored significantly higher in terms of their leadership skills (with older girls, for example, 38\% more likely to hold a leadership position at school) and were $70 \%$ more likely to have worked with others to solve a community problem (possibly reflecting the skills developed in the social innovation labs).

In terms of safety and support, the evaluation findings suggest that Makani participants are more likely to be able to identify and report age- and gender-based forms of violence, including physical, sexual, and verbal violence. Younger boy participants (aged 10 to 14 years) and older girl participants (15 to19 years old) were 19\% and 30\%, respectively, more likely than their non-participant counterparts to know where to seek support for incidents of violence, for example.

The evaluation findings also suggest that Makani participants are developing the communication and negotiation skills needed to forge stronger and more healthy relationships. Within their family life, older adolescent participants were significantly more likely to discuss issues (e.g., education, future work life, relationships, religion) with their parents and the improvements were especially strong in terms of communicating with their fathers $(21 \%)$, whilst older adolescent girls reported that they were more likely to enjoy improved mobility outside the home (25\%). With their peer networks gains were also significant; adolescent girls who attend Makani were $16 \%$ more likely to have a trusted friend, while older boys were $16 \%$ less likely to report psychological distress.

\footnotetext{
2 Study respondents were all part of a cash transfer waiting list meaning that their households had been assessed as highly vulnerable (Jones et al., 2019).
} 


\section{Agency and Empowerment for Adolescent Girls}

The Makani centers have become increasingly run by local community organizations over time, which enabled Makani to pivot rapidly at the onset of the COVID-19 pandemic. With the closure of physical centers, Makani communicated with participants and their families via text and WhatsApp messages and videos, providing information about virus prevention, psychosocial resilience for young people and their caregivers, as well as online education support. Among GAGE respondents, telephone survey findings found that during the lockdown and school closures, $35 \%$ of participants reported receiving support of some kind from the program, including messaging around resilience, coping with stress and online education options. GAGE qualitative data highlighted that this support was especially important to adolescent girls who faced heightened social mobility restrictions during the lockdown due to discriminatory gender norms, whereas boys still had some opportunities to socialize with peers (Malachowska et al., 2020).

Makani has, however, had more limited impact in embedding a gender-transformative approach within its broader package of support. On the one hand, as noted above, the program teaches both boys and girls to recognize and report different forms of age- and gender-based violence (verbal, physical, psychological, and sexual), and it includes awareness-raising activities around the harms of child marriage targeted at adolescents and parents. On the other hand, however, both adolescents and parents in the GAGE qualitative findings highlighted that these sessions did little to shift the broader enabling environment and underlying gender norms, that few referrals were made by program facilitators with regard to girls at risk of impending child marriages, and that the program also reaches very few married adolescent girls. Moreover, because sessions are usually single-sex only, with the exception of the social innovation labs, there are fewer opportunities for Makani to tackle gender discriminatory norms and practices.

\section{Empowerment + Engagement $=$ Equality, Malawi, Kenya and Uganda}

In 2015-2016, a core group of 1,000 young women and adolescent girls, including 125 young women living with HIV, from Malawi, Kenya, and Uganda led a pilot project that strengthened the leadership of young women and adolescent girls in the AIDS response. Called "Empowerment + Engagement = Equality," the program built stronger leadership among young women and adolescent girls to engage in national assessments initiated by the All In to \#EndAdolescentAIDS platform. The program addressed the issue of unequal gender norms that heighten adolescent girls' vulnerability to HIV infection, provided safe spaces where experiences 


\section{Agency and Empowerment for Adolescent Girls}

can be shared, and increased leadership and participation skills of young women and adolescent girls to be vocal in the decision-making processes.

The initiative, designed and implemented by UN Women and the International Planned Parenthood Federation, mobilized more than 1,000 young advocates, including young women living with HIV, to voice their concerns at the local, regional, and national levels. As well as sharing knowledge among themselves, the participants engaged in face-to-face and online meetings with parents, teachers, religious leaders, and other community stakeholders to discuss how to change harmful gender norms and inequalities that increase the risk of HIV infection. This also resulted in a greater level of knowledge and awareness about gender equality and HIV issues. During a very short period of time, these young activists were able to reach more than 10,000 other young people through digital, social, and print media. The young women and adolescent girls in Malawi and Kenya set up WhatsApp and Facebook groups to share ideas on how to promote gender equality in the context of HIV, provide peer-to-peer support and mobilize for joint action.

The former First Lady of Malawi, Gertrude Mutharika, participated in one of the discussions and committed her support to challenging the issues that increase the risk of HIV infection among young women, including gender-based violence. The young leaders have continued to advocate at the highest levels, taking part in debates at the International AIDS Conference in Durban, South Africa, in July 2016.

The estimated 280,000 young women (15 to 24 years) who newly acquired HIV in 2019 marked a 34\% decline since 2010, but that number was almost 3 times larger than the 2020 target of fewer than 100,000 per year by 2020 of the Political Declaration on HIV/AIDS. Young women aged 15 to 24 years make up $10 \%$ of the population in sub-Saharan Africa but account for $24 \%$ of new HIV infections in that region. Knowledge about HIV prevention among young women is alarmingly low, with only about one-third of young women in sub-Saharan Africa having comprehensive knowledge about HIV. Among 197 countries only 47 reported having no laws requiring parental consent for adolescents to access sexual and reproductive health services in 2018 (UNAIDS, 2020). Research shows that when girls stay and finish secondary school, the chance of getting HIV is reduced by $50 \%$. In an effort to promoting the voice and engagement of young women and adolescent girls as advocates and leaders, executive leadership of UNAIDS, UN Women, UNFPA, UNESCO, and UNICEF are working closely to design a new joint initiative with and for adolescent girls and young women in Africa "Education Plus" (Byanyima et al., 2020). The initiative is focused on promoting universal secondary education and the 


\section{Agency and Empowerment for Adolescent Girls}

enabling environment for advancing gender equality and empowering young women and girls to prevent HIV and mitigate its impact.

\section{Concluding Words: Implications for Policy and Practice}

Adolescent girls continue to face significant obstacles to fulfilling their potential. They are more likely than their male peers to lack access to and drop out of secondary school, contract HIV, and be exposed to sexual violence and harmful practices such as child marriage (UNICEF et al., 2020). Girls are frequently overlooked in emergencies and the COVID-19 pandemic risks setting girls even further off track, compromising country efforts to achieve the Sustainable Development Goals (UNFPA \& UNICEF, 2020).

Evidence-informed approaches to support adolescent girls' health and well-being are increasingly available, but greater investments in these solutions are needed, especially in the COVID-19 context. As governments prepare national response and recovery plans it is essential that adolescent girls' rights be prioritized.

Of great concern is the need to have effective scalable interventions that reach all girls. Despite demonstrating positive results, most girl-intentional programs have not reached national scale. The reopening of schools provides a unique opportunity to meaningfully adapt to better respond to the multidimensional needs of girls, while recognizing the disproportionate constraints they experience. For contexts where many girls are out of school, online programs scaled through national universities, and/or social protection provide other opportunities to widen reach. Entry points to intentional girl-focused programming will differ depending on context. Promising approaches include more consistent support for girls' education and training (including nonformal to formal education bridging initiatives and market-responsive technical and vocational training); violence prevention efforts that specifically target adolescent girls (Ellsberg et at., 2017); combining economic interventions like cash transfers with girls' empowerment and social services to address household poverty (Austrian et al., 2018; Gentilini et al., 2020); promoting girls' participation and agency (Temin \& Heck, 2020); and specifically tailoring health and other social services to adolescent girls' needs (UNICEF \& Population Council Institute, 2020).

Reforms in public health are particularly relevant in the COVID-19 context. A critical opportunity is to assure the inclusion of adolescent-girl-centered approaches that recognize agency and effective adolescent engagement into expanded universal health coverage, so that access to gender-responsive quality promotive, preventative, reproductive, and curative services are 


\section{Agency and Empowerment for Adolescent Girls}

available. Universal health coverage with its focus on three interlinked policy areas-service delivery, financing and governance-offers significant scalable opportunities to equitable progress in reducing some of the most pernicious barriers to the realization of adolescent girls' rights (WHO, 2017). It also has a role in shaping attitudes and behaviors-including supporting gender transformation and fostering positive norms-that can change future risk and improve adolescent girls' resilience. Central to the effectiveness of such systems will be recognition of the specific health and developmental needs of adolescent girls, including adolescent autonomy and agency in decision making (including support for the emotional aspects of decision making and access to peer networks and safe spaces), concerns around stigma and discrimination, expectations of privacy, and meaningful involvement of parents or guardians.

At the same time, there is a growing number of global initiatives designed to carry girls' voices into policy and political processes. The Generation Equality Youth Task Force and NGOs (Plan International, Terre des Hommes, Defence for Children, and ECPAT) partnered with groups of adolescent girls across the world to understand their specific concerns and build a Girls' Platform for Action to shape the Generation Equality forum (UN Women, 2020a). They identified gender-based violence, education and health as priority areas to achieve gender equality. Adolescent girls want their specific needs to be included and the opportunity to have their voices heard at all decision levels.

Complementing these important fora, we need to support efforts to advance operational learning and close knowledge gaps in a number of priority areas including integration or bundling of services across multiple platforms such as schools, health facilities and communitybased initiatives as well as understanding the implementation science of development accelerators such as cash-plus approaches which have the potential to impact across domains of girls' lives.

Overall, inter-sectoral solutions that address the myriad of issues affecting an adolescent girl's life require greater emphasis by governments, multilateral agencies, and NGOs across a range of settings, including emergencies. These interventions-with a strong focus on tackling gender inequities-should begin in early childhood and adolescence before gender inequalities become embedded (Kennedy et al., 2020). 
Journal of Youth Development | http://jyd.pitt.edu/ | Vol. 16 Issue 2-3 DOI 10.5195/jyd.2021.1071

Agency and Empowerment for Adolescent Girls

\section{References}

Austrian, K., Soler-Hampejsek, E., Mumah, J., Kangwana, B., Wado, Y., Abuya, B., Shah, V., \& Maluccio, J. 2018. Adolescent girls initiative-Kenya: Midline results report. Nairobi: Population Council.

Banati, P., \& Camilletti, E. (2018, October 3). Three windows of opportunity: Using science to inform programming for adolescents and young people. UNICEF Evidence for Action.

https://blogs.unicef.org/evidence-for-action/three-windows-of-opportunity-for-adolescents/

Banati, P., Jones, N., \& Youssef, S. (2020). Intersecting vulnerabilities: The impacts of COVID-19 on the psycho-emotional lives of young people in low-and middle-income countries. The European Journal of Development Research, 32, 1613-1638. https://doi.org/10.1057/s41287-020-00325-5

Banati, P., \& Lansford, J. E. (2018). Introduction: Adolescence in a global context. In P. Banati \& J. E. Lansford (Eds.), Handbook of adolescent development research and its impact on global policy, (pp. 1-26). https://www.unicef-irc.org/publications/pdf/AdolescentHandbook.pdf

Bashi, G., Martelotte, L., Modungwa, B., \& Olmos, M. E. (2018). Young feminists' creative strategies to challenge the status quo: A view from FRIDA. Gender \& Development, 26, 439-457. https://doi.org/10.1080/13552074.2018.1526464

Byanyima, W., Azoulay, A., Kanem, N., Fore, H., \& Mlambo-Ngcuka, P. (2020). Why we're uniting in support of African girl leaders to beat AIDS \& shift power. http://www.ipsnews.net/2020/10/uniting-support-african-girl-leaders-beat-aids-shift-power/

Camilletti, E. (2018). Realizing an enabling environment for adolescent well-being: An inventory of laws and policies for adolescents in South Asia. UNICEF Office of Research-Innocenti. https://www.unicef-irc.org/publications/pdf/WP\%20camilletti\%209.pdf

Carrico, A. R., Donato, K. M., Best, K. B., \& Gilligan, J. (2020). Extreme weather and marriage among girls and women in Bangladesh. Global Environmental Change, 65, Article 102160. https://doi.org/10.1016/j.gloenvcha.2020.102160

Catalano, R. F., Skinner, M. L., Alvarado, G., Kapungu, C., Reavley, N., Patton, G. C., Jessee, C., Plaut, D., Moss, C., Bennett, K., Sawyer, S. M., Sebany, M., Sexton, M., Olenick, C., \& Petroni, S. (2019). Positive youth development programs in low-and middle-income countries: A conceptual framework and systematic review of efficacy. Journal of Adolescent Health, 65(1), 15-31. https://doi.org/10.1016/j.jadohealth.2019.01.024

Chandra-Mouli, V., Lane, C., \& Wong, S. (2015). What does not work in adolescent sexual and reproductive health: A review of evidence on interventions commonly accepted as best practices. Global Health: Science and Practice, 3(3), 333-340. https://doi.org/10.9745/GHSP-D$\underline{15-00126}$

Das, J. K., Salam, R. A., Lassi, Z. S., Khan, M. N., Mahmood, W., Patel, V., \& Bhutta, Z. A. (2016). Interventions for adolescent mental health: An overview of systematic reviews. Journal of 
Journal of Youth Development | http://jyd.pitt.edu/ | Vol. 16 Issue 2-3 DOI 10.5195/jyd.2021.1071

Agency and Empowerment for Adolescent Girls

Adolescent Health, 59(4), S49-S60. https://doi.org/10.1016/j.jadohealth.2016.06.020

health.2016.06.020

Ellsberg, M., A. Vyas, A., Madrid, B., Quintanilla, M. Zelaya, J., \& Stöckl, H. (2017). Violence against adolescent girls: Falling through the cracks? Background paper. (Ending Violence in Childhood Global Report 2017). Know Violence in Childhood.

https://globalwomensinstitute.gwu.edu/sites/g/files/zaxdzs1356/f/downloads/Falling\%20through \%20the\%20Cracks Background\%20Paper\%20(1).pdf

Gentilini, U., Almenfi, M., Orton, I., \& Dale, P. (2020). Social protection and jobs responses to COVID-19: A real-time review of country measures. World Bank. https://openknowledge.worldbank.org/handle/10986/33635

Gharabaghi, K., \& Anderson-Nathe, B. (2018). Children and youth in the era of climate change, Child \& Youth Services, 39(4), 207-210. https://doi.org/10.1080/0145935X.2018.1557882

Harper, C., Jones, N., Marcus, R., Bantebya, G. K., \& Ghimire, A. (2018). Empowering adolescent girls in developing countries: Gender justice and norm change. Routledge. https://doi.org/10.4324/9781315180250

International Labour Organization. (2010). Vulnerable employment and poverty on the rise, Interview with ILO chief of employment trends unit. https://www.ilo.org/global/about-the-ilo/mission-andobjectives/features/WCMS 120470/lang-en/index.htm\%200R\%20https://esa.un.org/unmigration/documents/retreat/UN\%20WOMEN Ind icator vulnerable employment.pdf

Jones, N., Devonald, M., \& Guglielmi, S. (2019). Leave no adolescent behind: The gender- and agespecific vulnerabilities of adolescent refugees and IDPs (Policy note).Gender and Adolescence Global Evidence. https://www.gage.odi.org/publication/leave-no-adolescent-behind-the-genderand-age-specific-vulnerabilities-of-adolescent-refugees-and-idps/

Jones, N., Małachowska, A., Guglielmi, S., Alam, F., Abu Hamad, B., Alheiwidi, S., \& Yadete, W. (2020). 'I have nothing to feed my family . . . ': Covid-19 risk pathways for adolescent girls in low-and middle-income countries (Report). Gender and Adolescence: Global Evidence. https://www.gage.odi.org/publication/i-have-nothing-to-feed-my-family-covid-19-risk-pathwaysfor-adolescent-girls-in-low-and-middle-income-countries/

Jones N., Presler-Marshall, E., \& Lunin, L. (2018, June). Accelerating adolescent girls' education and empowerment: $A$ call for action to the G7(Policy Brief). Gender and Adolescence: Global Evidence. https://www.gage.odi.org/publication/accelerating-adolescent-girls-education-andempowerment-call-action-g7/

Kennedy, E., Binder, G., Humphries-Waa, K., Tidhar, T., Cini, K., Comrie-Thomson, L., Vaughan, C., Francis, K., Scott, N., Wulan, N., Patton, G., \& Azzopardi, P. (2020). Gender inequalities in health and wellbeing across the first two decades of life: an analysis of 40 low-income and middle- 
Journal of Youth Development | http://jyd.pitt.edu/ | Vol. 16 Issue 2-3 DOI 10.5195/jyd.2021.1071

Agency and Empowerment for Adolescent Girls

income countries in the Asia-Pacific region. The Lancet Global Health, 8(12), e1473-e1488. https://doi.org/10.1016/s2214-109x(20)30354-5

Kerr-Wilson, A., Gibbs, A., McAslan Fraser E., Ramsoomar, L., Parke, A., Khuwaja, H. M. A., \& Jewkes, R. (2020). A rigorous global evidence review of interventions to prevent violence against women and girls. WhatWorks to Prevent Violence.

https://www.whatworks.co.za/documents/publications/374-evidence-reviewfweb/file

Lassi, Z. S., Moin, A., Das, J. K., Salam, R. A., \& Bhutta, Z. A. (2017). Systematic review on evidencebased adolescent nutrition interventions. Annals of the New York Academy of Sciences, 1393(1), 34-50. https://doi.org/10.1111/nyas.13335

Lerner, R. M., Lerner, J. V., Almerigi, J. B., Theokas, C., Phelps, E., Gestsdottir, S., Naudeau, S., Jelicic, H., Alberts, A., Ma, L., Smith, L. M., Bobek, D. L., Richman-Raphael, D., Simpson, I., Christiansen, E. D., \& von Eye, A. (2005). Positive youth development, participation in community youth development programs, and community contributions of fifth-grade adolescents: Findings from the first wave of the 4-H study of positive youth development. The Journal of Early Adolescence, 25(1), 17-71. https://doi.org/10.1177/0272431604272461

Majeed, H., \& Lee, J. (2017). The impact of climate change on youth depression and mental health. The Lancet Planetary Health, 1(3), e94-e95. https://doi.org/10.1016/S2542-5196(17)30045-1

Małachowska, A., Al Abbadi, T., Al Amaireh, W., Banioweda, K., Al Heiwidi, S., \& Jones, N. (2020, May). Listening to young people's voices under COVID-19. Exploring the impacts of COVID-19 on adolescents in Jordan's refugee camps and host communities (Policy Brief). Gender and Adolescence: Global Evidence. https://www.gage.odi.org/wp-content/uploads/2020/05/Exploringthe-impacts-of-covid-19-on-adolescents-in-Jordan\%E2\%80\%99s-refugee-camps-and-hostcommunities-1.pdf

Malhotra, A., Warner, A., McGonagle, A., \& Lee-Rife, S. (2011). Solutions to end child marriage: Summary of the evidence. International Center for Research on Women. https://www.icrw.org/wp-content/uploads/2016/10/19967 ICRW-Solutions001-pdf.pdf

Petroni, S., Das, M., \& Sawyer, S. M. (2019). Protection versus rights: Age of marriage versus age of sexual consent. The Lancet Child \& Adolescent Health, 3(4), 274-280. https://doi.org/10.1016/S2352-4642(18)30336-5

Population Council. (2020). BALIKA (Bangladeshi Association for Life Skills, Income, and Knowledge for Adolescents). https://www.popcouncil.org/research/balika-bangladeshi-association-for-life-skillsincome-and-knowledge-for-ado

Shrestha, S., \& Wærdahl, R. (2020). Girls' access to adolescent friendly sexual and reproductive health services in Kaski, Nepal. Asia \& The Pacific Policy Studies, 2020(7), 278-

292. https://doi.org/10.1002/app5.305 
Journal of Youth Development | http://jyd.pitt.edu/ | Vol. 16 Issue 2-3 DOI 10.5195/jyd.2021.1071 Agency and Empowerment for Adolescent Girls

Simac, J., Marcus, R., \& Harper, C. (2019). Does non-formal education have lasting effects?. Compare: $A$ Journal of Comparative and International Education. https://doi.org/10.1080/03057925.2019.1669011

Temin, M., \& Heck, T. (2020). Close to home: Evidence on the impact of community-based girl groups. Global Health: Science and Practice, 8(2), 300-324. https://doi.org/10.9745/GHSP-D-20-00015

UN Women. (2017). Report of the expert group meeting on the CSW 62 priority theme: Challenges and opportunities in achieving gender equality and the empowerment of rural women and girls. https://www.unwomen.org//media/headquarters/attachments/sections/csw/62/egm/expert\%20g roup\%20report revised final.pdf?la=en\&vs=2252

UN Women. (2020a). About generation equality. https://www.unwomen.org/en/get-involved/beijing-plus25/about

UN Women. (2020b). COVID-19 and violence against women and girls: Addressing the shadow pandemic (Policy Brief No. 17). https://www.unwomen.org//media/headquarters/attachments/sections/library/publications/2020/policy-brief-covid-19-andviolence-against-women-and-girls-en.pdf?la $=e n \& v s=640$

UNAIDS (2020). Seizing the moment. Tackling entrenched inequalities to end epidemics. https://aids2020.unaids.org/report/

UNESCO. (2014). Teaching and learning: Achieving quality for all (EFA Global Education Monitoring Report). https://en.unesco.org/gem-report/report/2014/teaching-and-learning-achieving-qualityall

UNFPA \& UNICEF. (2020). Adapting to COVID-19: Pivoting the UNFPA-UNICEF global programme to end child marriage to respond to the pandemic. https://www.unfpa.org/resources/adapting-covid-19pivoting-unfpa\%E2\%80\%93unicef-global-programme-end-child-marriage-respond

UNICEF. (2020). COVID-19 - GBV risks to adolescent girls and interventions to protect and empower them. https://www.unicef.org/media/68706/file/COVID-19-GBV-risks-to-adolescent-girls-andinterventions-to-protect-them-2020.pdf

UNICEF \& Population Council Institute. (2020). Are more people adopting COVID-19 prevention measures? (COVID-19 Research Results Brief \#2). UNICEF and Population Council. https://doi.org/10.31899/pgy15.1064

UNICEF, UN Women, \& Plan International. (2020). A new era for girls. https://www.unicef.org/reports/new-era-for-girls-2020

World Health Organization. (2017). Global accelerated action for the health of adolescents (AA-HA!): Guidance to support country implementation. http://apps.who.int/iris/bitstream/handle/10665/255415/9789241512343-eng.pdf?sequence=1

World Health Organization. (2018). WHO recommendations on adolescent sexual and reproductive health and rights. https://apps.who.int/iris/bitstream/handle/10665/275374/9789241514606-eng.pdf 
Journal of Youth Development | http://jyd.pitt.edu/ | Vol. 16 Issue 2-3 DOI 10.5195/jyd.2021.1071 Agency and Empowerment for Adolescent Girls

Wodon, Q., Male, C., Nayihouba, A., Onagoruwa, A., Savadogo, A., Yedan, A., Edmeades, J., Kes, A., John, N., Murithi, L., Steinhaus, M., \& Petroni, S. (2017). Economic impacts of child marriage: Global synthesis report. The World Bank and International Center for Research on Women. https://documents1.worldbank.org/curated/en/530891498511398503/pdf/116829-WP-P151842PUBLIC-EICM-Global-Conference-Edition-June-27.pdf

Woldeyesus, E. K., Domingo, P., \& Bekele, B. (2018). Policy and legal analysis notes: A review of the strategic plan for a multisectoral response to violence against women and children in Ethiopia (Policy Note). Gender and Adolescence: Global Evidence. https://www.gage.odi.org/publication/policy-and-legal-analysis-notes-ethiopia/ 